\title{
Identifying Academic Writing Problems Faced by Undergraduate Students at Shah Abdul Latif University Ghotki Campus
}

\author{
${ }^{1}$ Saeed Ahmed Rind \\ MS scholar Mehran UET Jamshoro \\ ${ }^{2}$ Dr. Ambreen Shahriar \\ Associate Professor IELL University of Sindh \\ ${ }^{3}$ Ms. Sadia Aftab Memon \\ Lecturer Mehran UET Jamshoro
}

\begin{abstract}
It has always been a challenging task for the students at undergraduate level to have mastery in English academic writing. The researcher being a teacher, at the locale of the study had particularly observed that at undergraduate level at Shah Abdul Latif university Ghotki campus, the students are not even able to produce a well coherent and cohesive write-up, when it come to their academic writing in English. This observation persuaded the researcher to investigate and to identify the problems that hinder them in English academic writing. Thus, the study was conducted with an aim to identify the problems that students at Shah Abdul University Ghotki campus face in English Academic writing. The population of this study was the undergraduate students of Shah Abdul Latif University Ghotki Campus. In this connection, purposive sampling technique was employed to select a representative sample from the above mentioned population. The sample for the data was twenty enrolled undergraduate students of Shah Abdul Latif University Ghotki Campus. The design of the study was purely quantitative. The students were asked to write/type an essay on a topic of their choice by using a computer. Their write-ups were analyzed with the help of Markin 4.Ink software. Moreover, the analysis was cross-checked by two (03) other experts in order to establish the reliability of the study. The results showed that most of the students were facing the problems like, sentence formation, subject-verb agreement, punctuation, lack of ideas and vocabulary etc. As a future implication the researcher shall try to design a study to study the causes of the academic writing problems that these students face.
\end{abstract}

Key words: Academic writing, English language, Error Analysis, Content Analysis, writing problems.

DOI: $10.7176 /$ RHSS/10-2-07

Publication date: January $31^{\text {st }} 2020$

\section{INTRODUCTION:}

1.1 ACADEMIC WRITING

Academic writing is defined as a type of writing done in the academic contexts for the academic needs. The institutions where it is required can be: college or university. Moreover, researchers, with the help of academic writing skill, become able to get their research work published. It enables them to either get their work published or to present in a research conference.

Academic writing has its own defined rules and parameters. One must abide by such rules and regulations while writing. That is to say, the writer must organize his or her idea in a clear way with required references and citations to avoid plagiarism. (Altakhaineh, 2010; Moore \& Murray, 2006; Nampala, 2010).

According to Morley-Warner (2009) academic writing is the one that is formal. It is a well-structured writing having formal vocab, grammar and syntactic structures. Additionally, a writer must provide arguments with authentic references which is the core of an academic write-up. Hence, it is a formal way of communication in an institution.

\subsection{CHARACTERISTICS OF ACADEMIC WRITING}

Academic writing has its own principles and parameters which constitute its unique style. It is unique in a way that it is not for the sake of entertainment but for providing the reader with the authentic information which one requires (Altakhaineh, 2010). It becomes clear that academic writing is aimed at informing, exploring, findingout, influencing and describing (English for Academic Purposes Guide, 2013). Therefore, it is characterized as 
the one reflecting, accuracy, objectivity, referencing and formality. By objectivity, in academic writing, it is clear that the writer has to avoid from the use of the first and the second personal pronouns. This enables a writer not to intervene and provide the factual and unbiased information. This is achieved by using the third person pronouns: he, she, it, they and passive structures are preferred (Mirza, n.d).

Accuracy is very crucial in academic writing, because, the writer must be proficient in the use of correct grammatical structures. He or she must use correct syntactic structures; use formal vocabulary. Additionally, punctuation must be correctly used. This shall enable the reader to comprehend the text clearly with any kind of ambiguity (Altakhaineh, 2010).

Moreover, the writer is expected and ought to provide facts and must avoid providing what are known as opinions, because, opinions are not factual and are of no use when it comes to academic writing. Furthermore, the writer must give his write-up a proper format.

Similarly, referencing is also very much important in academic writing. There are a number of ways to add referencing in an academic write-up. Some of such referencing styles are: American Psychological Association aka (APA), Harvard, Chicago etc. But, an academician must use only one of the referring systems which is allowed of preferred by his or her respected institution. Hence, when a writer finds an authentic concept then it must be followed by proper referencing and citation. The citations are to be in the end of the concept in the text, whereas, the complete refence must be put in the end of the writing on a separate sheet of paper (Cornwell \& Robertson, 2011; Publication Manual of American Psychological Association, 2001).

In addition to the afore-mentioned characteristics, formality is also of great importance in academic writing. It is written in a formal style which differentiates it from the other types of writings, such as, letters, emails or stories. Slangs and colloquial must be avoided in academic writing (Davies, 2008). Furthermore, the writers are also directed to avoid the use of abbreviated forms in it.

\subsection{THE STRUCTURE OF ACADEMIC WRITING}

Organization of academic writing is different from the organization of other texts. Academic texts are generally divided into three main parts: Introduction, Body and Conclusion. The introductory part includes the introduction of topic and what is to be focused in an essay (Awelu, 2011). This is the part where the writer has to impress one's readers and to inform them about the ideas that are to be discussed throughout his essay. This is the part where a writer has to provide definitions of key concepts and the related terminology (English for Academic Purposes Guide, 2013; Greetham, 2001; Jones, 2015; Whitaker, 2009).

After this part, comes the second part of an essay which is also called the heart of an essay. This part is consisted of a chain of paragraphs closely connected together. The task of a writer here is to maintain transition between the paragraphs, so that one idea may give way to the idea that follows it. Moreover, these paragraphs are developed to support one's thesis statement which is included in the introductory part of essay. Each paragraph in the body starts with a key sentence which keeps the transition in an essay. Furthermore, it is of vital importance that these key sentences must follow evidence-based argument (Jones, 2015; Whitaker, 2009).

Finally, comes the concluding part of an essay. This part is mainly developed to summarize the main ideas that have been discussed throughout the essay. A conclusion must present the results and discuss the solutions of the discussed problems (Anderson and Poole, 2001; Awelu, 2014)..

\subsection{STAGES OF ACADEMIC WRITING}

Essay is a product of an arranged system of writing which starts with the development of a simple argument and ends as a complete body of paragraphs intended to convey evidence and argument-based knowledge to one's audience. In this connection, students are taught to follow a process-based approach which enables them to comprehend the process through which an essay is developed. This approach of writing is acceptable widely. (Badger and White, 2000).

The students are generally expected to follow this approach because it is clear that writing is not something that is a produced through magic, but it is developed through a lot of hard work and practice.

While applying this approach a teacher ought to play the role of a facilitator and of the one who just provides scaffolding. He must remain closely attached to his pupil for guidance, help and required feedback. Resultantly, the pupils shall be able to master their essay writing skill. But, it must be understood these students need scaffolding 
at every stage of process-based approach. The stages of this approach are: Pre-writing, Planning, Drafting, Revising, Editing and Proof-reading. All these stages are being discussed below.

Pre-writing is a stage at which the writer begins brainstorm the ideas that he needs to include in his essay. But, for brainstorming, he must at first understand the topic completely. The writer must have a look at the topic; must decide its scope and its audience. This step follows planning. At this stage the writer is expected to find out the sources of information and must draw a rough outline of his essay. Most importantly, the writer in these two stages must discuss the topic with the concerned fellows who can provide him information regarding that.

Planning precedes writing. The writer here, on the basis of his rough outline tries to write multiple drafts. Here they are not supposed to be worried about their grammatical mistakes. The main focus is to put the relevant material which can clearly convey his message to the audience. Afterwards, the writer has to go through the stage known as revising. At this stage he has to revise the content that he has put in the text. Moreover, he has to provide his draft to a more knowledgeable other (MKO) for assessment. Then, he has to revise his draft based on the feedback of the assessor (Awelu, 2014; Langan, 2014; Yan, 2005).

The revising follows editing. The writer has to incorporate all the changes that he has been told in the feedback. Here, the draft is checked for spellings, capitalization related errors, grammar, syntactic structures etc. Finally, the text or what is particularly known as essay becomes ready after its tuning and proof-reading (Anderson \& Poole, 2001; Awelu, 2014; Davies, 2008; Greetham, 2001).

\section{Literature Review}

\section{Academic writing in Pakistan}

In Pakistan Higher Education Commission emerged to play a vital role in the development of university level education. Since its establishment, it has provided a great number of national as well as international scholarships to scholars in Pakistan (Laghari 2009). And, from 2003 to 2008 HEC (Higher Education Commission) setup more than fifty new universities and allowed the administration of those universities to setup their affiliated campuses in the far flung areas of the country 'The DAWN' (2012).

Since the vital and only source of getting education at the university level is to master English language. In this connection, Britain has designed a new sort of courses including English for Academic Purposes (EAP) as has been provided in Journal of English for Academic Purposes (2002 pp.69-72). It becomes very much important for HEC to promote EAP at undergraduate as well as at the postgraduate level, so that the scholars can enhance their language proficiency particularly academic writing. As a general observation, it has been noted that the traditional language courses, including both methods and techniques that a teacher implies to teach students, are not producing desired results, when it comes to student's academic writing. As provided by Woodward-Kron, (2002) academic writing is misconceptualized as plain writing by certain naïve writers. It is actually the writing that requires an academic writer to possess evolutionary and analytical skills.

English is a source of communication which is global in nature. It connects the peoples of the world. It connects them for relative purposes like; trade commerce, education etc, (Vency H.J, E. Ramganesh (2013). In this connection HEC introduced certain goals aimed at improving the yardstick for measuring the quality of academicians started being judged by the number of their publications. HEC also facilitated the academicians and researchers by providing them free internet access to a number of national and international journals (Akbari and NAqvi 2008). However, there is much need of help to improve the academic writing skills of researchers in general and undergraduate students in particular.

In this connection all the studies that were conducted afore, reveal the students in particular face a great number of problems when it comes to their academic writing. They particularly have problem in the usage of tenses, ambiguity in sentences, unparallel sentence structures, poor vocabulary and style of writing, poor paraphrasing, error in pronouns, articles, punctuation etc. They even have no knowledge of different text types and no knowledge of how to coherently combine them. Hyland, (2003, p.19).

\section{Problems in English academic writing}

Writing is considered a difficult skill for learning a language specially a second or a foreign language, because, it involves using a language strategically, accurately and efficiently (Dar \& Khan, 2015; Hyland, 2003; Mahboob, 2014). Academic writing is generally conceptualized as scientific writing that is used by scholars in their respective field of research. Writing ability is very much important for a academician. The ability to produce a coherent and meaningful write-up helps him or her to achieve marvels in academic field. But, mastering academic writing seems very much difficult for scholars. Because, it is seems very much complex for them (Negari, 2011). Negari points out that there are certain problems, 
ranging from word spelling to the development of an argument, which students face while writing a report or an essay. Alsamadani (2010) provides that academic writing involves the process of developing an argument on the basis of a thesis, support the thesis with certain facts and figures, organizing what one intends to write and finally revising and editing them to ensure effectiveness and free of error writing. Moreover, Musa (2010) considers writing a skill which is difficult to learn. It is difficult because it includes numerous components: spelling, punctuation and a complete command on the grammatical usage of lexical units and syntactic structures. In this regard, the academic writing problems that students face differ context to context, that is to say, they are relative in nature. According to Noor (1996) as a result of various studies conducted in the context of Saudi Arabia most of the students face syntactic and grammatical problems in academic writing.

A writer as a matter of fact, in absence of prosodic features in writing, tries to connect his ideas through certain cohesive devices and tries to bring coherence in it, which makes it possible for his interpreter to understand the text (Byrne, 1998:4). In the same way, Hedge (1998:5) is of the view that as a writer has to compensate the prosodic features; he/she tries to organize the text with the use of cohesive devices, choice of vocabulary and complex grammatical structures.

Moreover, a student's writing skills are highly affected by certain writing problems, some of them are: grammatical problems, mechanical problems, syntactic problems and spelling problems. All these problems are being discussed below.

As far as the grammatical problems are concerned, a learner in this connection faces many of them when he/she tries to write in second language. Tyner (1987) is of the view that grammatically verbs take different forms based on the tense in which they are used and the subject that they take. This becomes a hurdle when it comes to their writing in second language. Additionally, Kharma (1987) asserts that students generally have problem in subject-verb agreement, pronoun referencing (deixis) and conjugation.

Similarly, proper arrangement of words to make sentences is also one of the big issues in ESL learners writing. Reid (1983) stated that various syntactic structures are reflected by a sentence. And, according to West (1996), the learners who are not capable use run-on, incorrect and fragmented sentences. Moreover, such students are also incapable of producing longer, compound or complex, sentences, because of less exposure of coordination and subordination (Kharma, 1986). Zamel (1983:22) emphasizes, though conjugation or cohesion is of great importance in writing, but, for English language learners these have been found very much problematic.

A writing that is reflects a varied range of vocabulary, used in a proper grammatical structures and with a varied syntactic stuructures is termed as good writing (Norish, 1983; Alamirew, 2005). When a writer practices a varied choice of vocabulary and keeps the concern of his reader in his mind, the composition produced by him seems sensible and comprehensive (Reid, 1983). But, it has been observed by White (1980) that students, in order to impress their reader or the examiner, use bug words and this leads to the problems in their diction. Hence, the proper use of words in their appropriate place is a big problem which the students face.

Another important problem termed as cognitive problem, which students face in their writing, includes a wide range of problems in it, these are: punctuation problems, capitalization problems, spelling problem, content problem and organizational problem.

Firstly, according to Bryne (1988: 16) the negligence to consider punctuation one of the important areas of composition makes it problematic for students to master it. The rules of applying punctuation are not universal which leads the students to face this problem in their writing (Carrol and Wilson, 1995:191).

Secondly, Kroll (1991) writes that the use of capital letters for initials of sentence, in proper nouns, topics and heading etc is very much useful. But, the learners face difficulty in the use of capitalization. And, there are a number of reasons for such misuse or no-use of capitalization in writing English as a Second language. It is because the rules related to capitalization and classification of nouns into proper nouns and common nouns are not universal in nature (Gowere et al,. 1995). 
Thirdly, spelling system of English language has become problematic for students due to a number of reasons. Growere et al 1995, provide that influence of other languages, variations in pronunciation and certain historical developments in the language has made it complex for the students to overcome this problem.

Fourthly, content in writing is of great importance and it is the student who is rich in ideas becomes a good writer in a language in general and English language in particular. Clifford 1987 asserts that students who learn English as a second language and English as a foreign language face great difficulty in exploring and finding relevant content to include in their writing for the purpose of communication. And one of the reasons behind this is the traditional approach of teaching students. The mentors teach students speeling, punctuation and grammar as per the traditional methods. Clifford (1987) advises teachers to suggest their pupils to focus on their message and knowledge that they intend to convey rather than their grammatical structures which include spelling, punctuation, grammar etc.

Fifthly, students in writing English face problems in paragraph structuring, its topic development, and its structuring as a whole which includes a theme (Kharma, 1986). Students in this connection either do not make their paragraph limited to a single topic or the topic of their paragraph is not clearly exemplified (West 1966: in Tsegay 2006: 17). Another problem that the students face, according to Raimes, 1983, in organization of writing is the difficulty in differentiating a topic and its supporting ideas, generalizations and specific details. Moreover, learners face difficulty in the use of cohesive devices which makes it difficult for them to unite their paragraphs (Pincas, 1982).

\section{Academic writing problems in Pakistan}

Writing plays an important in production of a language. But, when it comes to writing in English language, its importance increases. It increases because of the status of English language which is considered a global means of communication (Marlina \& Giri, 2015; Rahman, 2002; Mansoor, 2005; Mahboob, 2014). Hyland (2003) in this connection is of the view that a learner's effectiveness and his or her language development are based on improvement in writing. Whatsoever an effective writer writes must be coherent, cohesive, logical, structured and properly organized and must reflect a varied choice of vocabulary (Jacobs \& L, 1981; Hall, 1988). But, writing is being undermined due to the way it language teaching is being practiced. Students are being taught on the basis of traditional methods like teaching grammar and syntax. According to Naun (1989) writng involves a complex cognitive processing, it expects a learner to master various factor attached to it. The factors are relative and vary from learner to learner. These might be variation of academic background, and numerous linguistic, psychological and cognitive phenomenon (Dar \& Khan, 2015; Haider, 2012).

As far as Pakistani English learners are concerned, these students have weak and substandard writing skills. Though the English language users have increased from 2\% in 1961 to $49 \%$ in 2003, they face a huge number of problems when it comes to their writing (Dar \& Khan, 2015). There issue emerge due to a learner's incompetence in syntax, coherence, expansion of idea, selection of content, topical sentence, conventions related to rhetoric, mechanics, organization of content, insufficient vocabulary and the use of vocabulary appropriately. That is why this area of language requires further research. Because, when one comes to know about the reasons behind the particular problems then one can address the problems effectively (Hyland, 2003).

Writing is almost challenging to master when it is the case of a second language. It requires a learner to be strategic in use of language, and having good syntactic accuracy with potential communicative skills (Dar \& Khan, 20115; Hyland, 2003; Mahboob, 2014). According to Kellogg (2001) writing is actually the test of one's ability to memorize, think, and express ideas successfully. Because, proficiency in composition of text shows how much effectively a learner has learnt a second language (Geiser \& Studley, 2002; McCutchen, 1984; Hyland, 2003; Nickerson, Perkins, \& Smith, 2014). Hence, learning of writing has gained very much importance because it is being considered an effective tool of communication and it is this tool through which plethora of researches are being published (Dar \& Khan; 2015; Graham \& Perin, 2007; Haider, 2012; Hyland, 2003).

Generally, the learners who are particularly students face a number of problems when they learn to write. The problems have been categorized into Linguistic, psychological, cognitive and pedagogical problems (Haider, 2012; Hyland, 2003). These learners face difficulty in structural areas of English. It is because the one who tries to comprehend the text has to process it mentally, and if he or she encounters and 
inappropriate structure then it becomes difficult to comprehend it (Quintero, 2008; Nik, Hamzah, \& Rafidee, 2010). Although a learner masters syntactic, lexical and grammatical areas of a language, he or she suffers from lack of confidence in because of an incoherent text that is produced by him or her (Rico, 2014). Lack of confidence in such students is attributed to the way of teaching or what is linguistically known as the method of teaching. Any method that does not conform to the learning style of a student and his or her cultural background then it becomes a cause of lack of confidence in him or her Ahmad et al., 2013). As a general argument poor writing skills are considered as a result of two factors: The mentor and the pupil. These are the teachers who lack appropriate way of teaching writing to a particular learner who lacks mastery in writing. These teachers do not provide any sort of feedback to learners and most importantly they lack the skill to motivate their learner. Whereas, there are numerous problems which students face in the process of learning. These problems are: lack of practice, low motivation, effects of first language and lack of reading. Pakistani students particularly English writers face psychological, cognitive, social and linguistic problems while writing their ideas ( Bila, Tariq, Din, Latif, \& Anjum, 2013; Dar \& Khan, 2015; Haider, 2012; Mahboob \& Talaat, 2008).

Students' writing skills are affected by numerous problems. These problems have a direct link with their level of motivation and their lack of clarity about the purpose and significance of writing in their second language. In the same way, Pineteh, 2013, pointed out that social media, lack of feedback from a teacher, the lack of analytical and evaluative approach in a learner and the number of students (size of their class) highly affect their writing skills and the text which are produced by them. Majority of the students in this connection, find it difficult to get sufficient and relevant information. They face difficulty in paraphrasing and summarizing information and most importantly in using an appropriate style of wriritng (Gonye, Mareya, Dudu, \& Sib, 2012; Kalikokha, 2008). There are numerous causes behind these problems. The main causes are: delay in instructions related to essay writing, negative attitude of students regarding English academic course, first language's interference and the lack of gap in communication between a learner and teacher to take constructive steps to address the problems that rise in the process of learning writing. Particularly, in Pakistan the causes are: lack of sufficient time to teach writing, improper audiovisual aids, large classrooms, traditional teaching methods and weak background of students. These factors highly affect the writing skills of the learners (Bilal et al., 2013; Butt \& Rasul, 2012). Additionally, the outdated textbooks (that neither improve writing skills nor give a learner an opportunity to enhance them) fail to attract the learners (Haider, 2012). Moreover, some researchers criticize teachers who are incompetent and emphasize the learners for rote learning and exam-oriented production of learning rather than focus on their creative skills (Mansoor, 2005; Rahman, 2002; Siddiqui, 2007). Writing skills are improvable and these can be improved by promoting the interest of learners, by motivating them and asking them to write for enjoyment through the help of technology (Graham \& Perin, 2007). As a remedy to ineffective writing skills, O'Malley \& Camot (1990) argue that meta-cognitive and cognitive strategies and be effectively used to enable students to know and pragmatically exercise writing process. Additionally, teachers can also play an important role, they can modify their teaching approaches by mutually designing certain motivating tasks that encourage student to liberally choose the topic of their choice (Pineteh, 2013; Quintero, 2008). Such strategies and modifications would help the writers to have control over their linguistic expression and command over domain specific knowledge. These would undoubtedly reshape their writing patterns by involving more practice and physical as well as cognitive skills (Kellogg\& Raulerson, 2007). This would enable the language as well as content teachers to monitor their students from the perspectives that are broad in nature (Nik, Sani, Kamaruzaman, Hasbollah Et al., 2010). Besides all, it is of great importance that the attitude of teachers and students towards writing and dealing with the problems related to it must be changed. The teachers must employ such strategies that help learners to jot down their verbal ideas on a piece of paper effectively, accurately and fluently. And, in order to boost up a student's confidence critical and effective feedback needs to be given. Such feedback according to Haider (2012) increases the confidence level of a learner. It benefits the scholars and the students who are involved in academics in a number of ways.

\subsection{Research Question:}

The present research addresses the following question:

1. Q.1 What are the main problems that students face in academic writing at Shah Abdul Latif University Ghotki campus? 


\section{Methodology}

3.1 Participants

Twenty students from different departments of Shah Abdul Latif university Ghotki campus were taken as a sample for the study. To select the sample, purposive sampling techniques was employed. The sample included participants from both gender groups.

\subsection{Data Collection}

Data collection is the most crucial and critical period of a research. The researcher started the collection of data by at first seeking permission for data collection from the authorities of the Shah Abdul Latif University Ghotki campus. After seeking permission consent forms were distributed among the students from whom the researcher intended to collect data, because the researcher had employed purposive sampling technique.

The researcher got the required number of respondents within two days, and, he started collecting data from the respondents. The respondents were gathered in the computer laboratory and there they were briefed about the research and the process through which they had to undergo. They could quit it if they wished to at any stage of the research, simply, they had been left on their own will.

Afterwards, they were told to type an essay, not exceeding 400 words, on a topic of their own choice. There was no limit of time as well. That is to say, they were given one an half hour to complete their write-ups.

As they were done they with their essays, the essays were analyzed with the help of software, 'Markin 4. Ink.'

\subsection{Instrument for data collection and tool for its analysis}

It has been already mentioned that the data was collected with the help of two separate tools. Markin 4. Ink software was used for the analysis of academic essays and thematic analysis for the analysis of the focus group interviews the results produced by 'Marki 4.Ink' were presented in descriptive and numerical form. This software is in use at different universities all over the world. This software helps in doing a speedy analysis or assessment of the write-ups produced by students. It not only helps in categorizing errors but also provides results of the errors in statistics, and definitely the analysis is very accurate. This software has been used in this study. At first, the researcher marked the errors in all the 20 write-ups of the subjects. Then, for credibility, or what is technical terms is called the validity, three other experts, in the field of academic writing, analyzed the write-ups in order to analyze and mark the errors made by the students of Shah Abdul Latif university, Ghotki campus.

\section{Results and Discussion}

\subsection{PROBLEMS FACED BY STUDENTS IN THEIR ACADEMIC WRITING}

\subsubsection{Formatting}

The first and foremost or what can be termed as the most important part of an essay is the way the ideas are put in an essay as per its academic format. As one can see the picture of the essays written/typed by the students, students have not put their essays in that format. Their essays lack a proper format. They have started it randomly and without developing a proper introductory paragraph.

\subsubsection{Markin 4.Ink based analysis of participants' write-ups}

As mentioned earlier in the methodology chapter (see section 3.3.4.1), the quantitative data was analyzed through Markin 4.Ink. This software not only helped in knowing the academic writing problems that the students face but also automatically generated statistical results of the instances in the write-ups. Moreover, the software helped in categorizing the problems as well. The results clearly show the problems their appearance and the categories to which they belong. The software provided the data in numerical form. The 
pie chart generated with the help of statistics is given below:

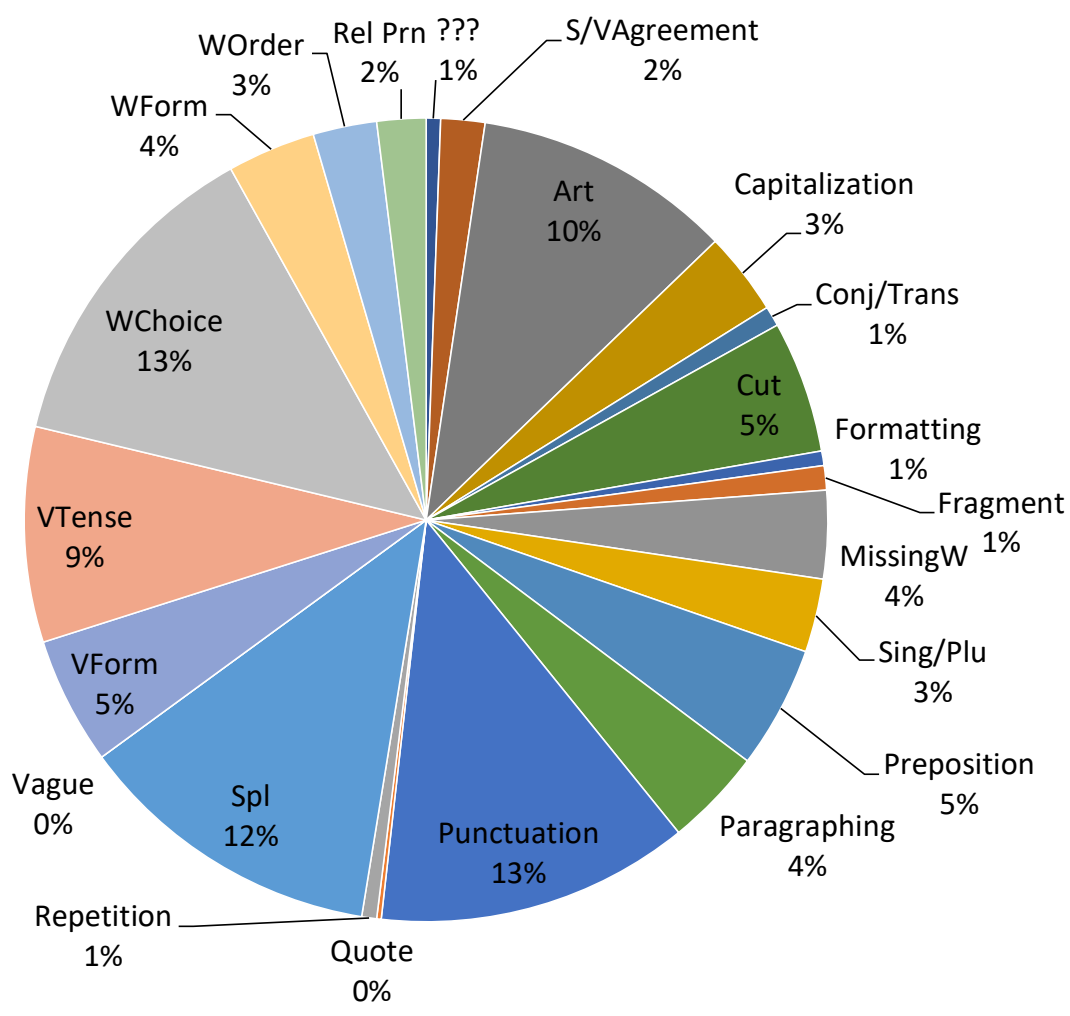

fig. 4.1: Instances in write-ups

The results of all the twenty (20) write-ups are being given below. Additionally, the statistics follow a detailed discussion about that as well. The academic problems of the students have been discussed categorically in the following sub-sections.

As far as the problems related to language proficiency and grammar are concerned, these are being categorized below:

a) Sense

The first category, generated by Markin 4.Ink, related of academic writing problems is sense. The tag 'sense' in Markin 4.Ink refers to the structures which have problems in conveying a complete sense to the reader. And, this can be because of certain problems. First of these problems occurs when a writer puts an irrelevant idea. This can be defined as an idea that has nothing to do with the topic of discussion or the topic which has been assigned to a writer. The writer while writing may put certain irrelevant ideas which may make the ideas stand out of the context, hence creating a sense of ambiguity and irrelevancy in the readers mind.

Some of the examples in this connection have being quoted in this section. These have been quoted from the write-ups which were written by the participants who participated in this study related to the academic writing problems of the students at Shah Abdul Latif University Khairpur, Ghotki campus. For example P1 wrote, "You are bought by God, what you will do and what you are doing here everything which you are doing Cut it is in the knowledge of God." In this example one can clearly see how the phrase 'which you are doing' is put unnecessarily in the sentence. It has brought senselessness in the sentence. Hence, it needs to be cut or omitted from the sentence. Similarly, another participant $\mathrm{P} 7$ wrote, "He recieves the respect as ${ }^{\text {Cut }}$ in education field with respect to others." In this example the word 'as' has been tagged as cut because it has been put unnecessarily. Moreover, P8 also had same sort of problem in writing. He/she had unnecessarily put the word 'that' in his one of the sentences. It was written like," Now I am sharing my observation that in our society that ${ }^{\text {Cut }}$ people are not giving complete rights to the women." Here the word 'that' must be cut as it makes the sentence senseless. 
There were similar kinds of problems in other write-ups as well. These problems were incomplete text, poor word choice, Wrong word form and in some cases unnecessary repetition of certain lexical items.

b) Problem in the use of verb

Verb is considered as the nucleus of a sentence or a clause. This determines not only the tense of the verb but also shows the number of the subjects it follows. In this study majority of the participants were facing problems in the use of verbs. This usage particularly included the wrong use of verb from, problem in the use of verb as per its tense and most importantly they could not put a verb that agrees with the subject it follows- subject verb agreement.

Firstly, in verb form related errors the total percentage (generated by Markin 4.Ink) of the errors was five

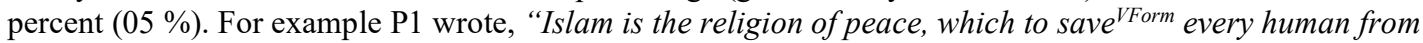
every war, although it would be a physically war or psychology war." In this case one can see that this sentence does not require an infinitive form of the verb 'save'. The student has committed an error by putting the verb in its infinitive form. There was another sentence having same kind of error which written by the same participant. In that sentence the participant put the verb 'mention'. The verb in this case did not agree with its subject. The sentence is, "Islam also mention ${ }^{\text {VTense }}$ all the extra activities of our life." Here the subject is singular in number, whereas, the participant has put the verb in its form which only agrees with a plural verb. P2 in this case wrote a sentence which belongs to first conditional sentence. As a rule the first conditional requires the verb to be written in its first or bare form. But, the participant wrote that sentence, "If I will do VTense the work," This sentence was marked as verb tense error as the sentence itself does not require the verb to be put with a future auxiliary verb, but it requires it to be in its simple or fist form. Similar kind of error was found in the write-up of P3. P3 wrote, "Each and everybody is has VTense equal right to have it in their life to live freely and happily." In this sentence the verb does not require to be accompanied by a copula. But, the participant has used a copula before the main verb has which in this case is referring to possession.

c) Subjectivity (the use of first personal pronoun) Subjectivity is defined as the use of first person pronoun in a write-up. As one of the rules in academic writing, the writer ought to avoid the usage of such pronouns in his/her academic write-ups, because, academic writing is not based upon subjective opinions but objective reality including facts and figures. But, the participants in this case have used such pronouns in their academic essays which makes them look a literary piece of writing rather than an academic write-up. For example, P20 wrote, "Firstly, to add more views regarding the topic I ${ }^{S U B}$ want to give an example that there is a hotel which is decorated very well and attracts to go there and raises a will to spend some time." One can clearly see in this sentence that the participant has used the first person pronoun in his write-up. This makes the write-up look subjective and based upon subjective reality which has been perceived by the participant herself/himself. The participant in this case could have avoided such subjectivity by transforming the sentence into its passive form. He could have started the sentence like: an example is being quoted/ for example/ for instance. Such expressions help to avoid subjectivity in case of academic writing. Another example related to such problem is being quoted from P16's write-up. The participant wrote, “As we ${ }^{S U B}$ know, what is society?" Here the participant has used the first person pronoun 'we'. The participant could have avoided subjectivity in this case by writing an expression 'It is known'. This would have brought objectivity in this case and would have helped him/her to avoid the use of first person pronouns in an academic write-up.

As seen above in the examples, the writers are facing such problems and the reasons behind such problems are still unknown in this case. Fortunately, the reasons behind such problems in case of academic writing problems at Shah Abdul Latif University Ghotki campus have been found by the researcher with the help of this study. The reasons and their solution to this problem have been discussed in the further sections.

d) Formatting

Another problem which was found in this case was related to the proper formatting of write-ups. The participants in this case were not able to put their knowledge in the essays in its proper format- an academic essay's format which is suggested to be followed in academic writing. For instance, the participants' writeups lacked a proper thesis statement; their write-ups were like a random accumulation of knowledge put together without any proper linkage- cohesion and coherence. Most of the students even had not properly concluded their essays. Hence, their essays lacked the feature of completeness. One of the essays has been given below as an example to support the above discourse related to formatting related problems. 


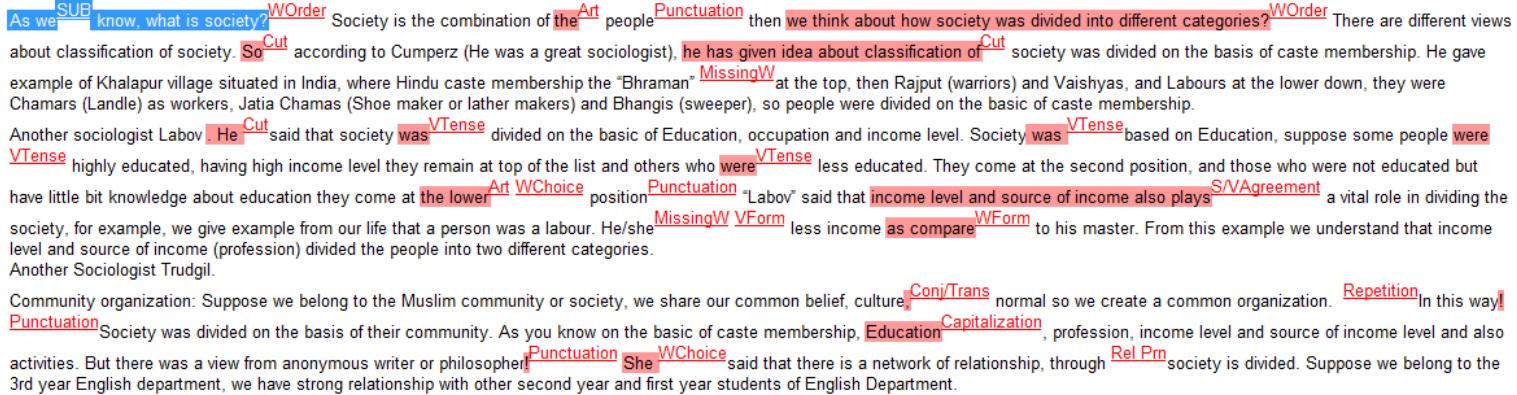

The picture clearly shows the way the essay has been written by the participant. This academic essay does not include any thesis statement. Moreover, if one closely looks for the format, one would find that thought the write-is divided into paragraphs, the paragraphs themselves are not according to its format- topic sentence, body and conclusion. However, format is an integral part of an academic write-up and formatting related problems really affect the writing skills of students at undergraduate level at Shah Abdul Latif University, Ghotki campus. And, finding out reasons behind such problems in this case seem very much crucial in order to polish academic writing skills of the students.

e) Grammar

The participants were also found to have a great number of grammatical errors in their academic essays. These errors were related to the use of singular and plural forms of words, writing correct spelling, putting a punctuation mark where necessary, putting an appropriate preposition, capitalizing certain words as per the rules of capitalization and supplying definite or indefinite articles where necessary. These grammatical errors really affect the quality being comprehensive for a reader.

As far as singular and plural related errors are concerned, the percentage of such errors is three $(03 \%)$. Majority of the essays have such errors. The participants were unable to put the words in their proper number related agreement. For example, P18 wrote, "No matter there are in different form Sing/Plu for suppose, Allah, Bhagwan, Eshwar etc." The participant in this sentence has put the word 'form' in its singular form, whereas, linguistic context requires it to be put in plural form. If the participant had written it like: they are in different form, the sentence would have become correct. Similar kind of error was committed by another participant. It was found in the write-up of P3. The participant wrote, "Each and every people Sing/Plu has equal right to have whether He/She." In this sentence the participant has put the plural form the word 'person', whereas, in this construction- as it is followed by each and every- the writer must put the word in its singular form 'person'. The sentence would have been correct if it was written like: Each and every person. Therefore, the students must have knowledge regarding the use of singular and plural forms of words. They must have a clear concept regarding their use. They must be taught these concepts and need to be told the way to put them according to their lexical relation in a syntactic structure.

f) Spellings

Additionally, the participants were found to have committed spelling related errors as well. In this connection, the total percentage of spelling related errors was: twelve percent $(12 \%)$. The participants wrote the words incorrectly. The spelling of the word 'services' was written as 'servics', 'decision' was written as 'decission'- decision as decision occurred twice in P20's essay.

disappointed by his decission. Firstly, to add more views regarding the topic $\mathrm{SUE}$ want to give an example that there is a hotel which is decorated very well and attracts to go there and raises a will to spend some time. Although, which is much expensive, but inspite of all, one goes and when He/she spends time, sees the worst servics ${ }^{\text {Spl }}$ and the worst food then he/she cries on his decission ${ }^{\text {Spl }}$ that why I came here. So Punctuation mean to nothing can be judged by its outer look.

Same as, if one has need of a book which he wants to read about but when purchasing the book he just looks at cover of the books and purchases but when he goes inside $\frac{\text { MissingW }}{\text { tries to find the }}$

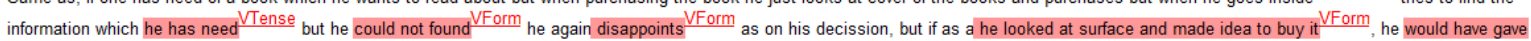
$\underline{V \text { Tense }}$ inside, it might not be disappointed WForm.

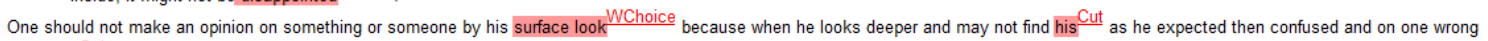
decission $^{\mathrm{Spl}}$, he makes mere wrong.

P19 wrote the word 'Lingua Franca' as 'Langia Francca'. This shows that participant lacked proficiency in writing words in their correct spellings. Similarly, the participant wrote 'completely' for 'completely'. The errors in spellings make the write-up difficult to comprehend for a reader. Hence, a writer must take care of his/her spellings while writing an academic write-up. This can affect the writer's grades in academics and 
the level of accuracy in language proficiency tests. Likewise, the writer would also face problems in conveying the message to his/her audience as well.

In addition to the above given grammatical errors, the participants had problem in supplying punctuation marks correctly in their academic essays. The misuse and omission of punctuation marks cause unnecessary breaks and fluency related problems in academic writing in particular and in writing in general. Therefore, the participants must try their level best to avoid such errors in their writing. As far as the participants' write-ups are concerned the percentage of the errors related to punctuation, in this case was: thirteen (13\%). The types of errors were mostly related to the use of comma, semicolon and full stop. This led to sometimes the occurrence of run-ons in the write-ups which affected the readability of write-ups. Some of the examples related to this case have been discussed further.

The first example is from P7's write-up. The participant wrote, "Education created scientists Punctuation teachers, doctors, engineers etc." As a rule related to the use of comma, the list of words is separated with the use of comma which is to be put in between the items in a list. Here the words: scientists, teachers, doctors and engineers, are a list of different professions. Hence, the words need to be separated from each other by supplying a comma in between the words. But, as the reader would see that the participant has not supplied comma after the word 'scientists', therefore, the participant has committed a common error in the use of punctuation marks.

Certain other problem which occurred in the write-ups of the participants, in case of grammatical errors, are related to the use of appropriate use of Preposition, capitalization and the use of articles. The total occurrence of grammatical errors in all the essays was: five percent $(05 \%)$, three percent $(03 \%)$ and ten percent $(10 \%)$ respectively.

\section{g) Syntax}

In syntax related errors the total percentage of the errors was four $(04 \%)$. Three of which was related to word order problems and one percent was related to sentence fragment.

The essays written by most of the participants, at syntactic level, were quite good. But, there were some write-ups which reflected these errors. For instance, one of the participants wrote a sentence, "As we know, what is society? WOrder" The structure of the sentence in this case requires it to be written in declarative form, whereas, the participant has written it in the form of interrogative. This type of error changes the sense of the entire message, as this form, interrogative form, shows that the participant is enquiring about the structure of a society. But, if one reads it in the given context, one shall find that the participant wants to convey that the reader is well aware of the structure of a society and he/she knows like how a society is made and of what it is made of. Hence, the mistake of not putting the words in their proper order has changed the meaning of the given sentence. The Participants in this regard, must be taught the proper word order of various types of sentences which they would use in their academic writing.

\section{Conclusion:}

The findings of the research are related to academic writing problems of students at Shah Abdul Latif University, Ghotki campus. The students in this regard were made to write an essay on the topic of their choice. The writeups were then analyzed with help of a software 'Markin 4.Ink'. The analysis was then cross-checked by three other experts in the field of academic writing. The results showed that the students faced a number of problems both in writing in academic essay and putting it in a proper format.

The results of the data showed that the students were facing problems in formatting of an essay. It can be defined as the students could not put their write-ups in a proper format of an essay. The students had problem in making the write-up coherent and cohesive. Their write-ups were also full of grammatical errors. These grammatical errors were related to grammatical category, syntax, morphology, subject-verb agreement, singular/plural, wrong use of relative pronouns etc. 


\section{References}

Al Fadda, H. (2012). Difficulties in academic writing: From the perspective of King Saud University postgraduate students. English Language Teaching, 5(3), 123-130.

Al Murshidi, G. (2014). UAE university male students' interests impact on reading and writing performance and improvement. English Language Teaching, 7(9), 57-63.

Altakhaineh, A. R. M. (2010). The main characteristics of good academic writing in English, language discourse functions, and challenges that Arab students face. UK. University of Salford.

Anderson, J., \& Poole, M. (2001). Assignment and thesis writing. Milton, Australia: Wiley \& Sons.

Awelu, A. (2011). Academic writing in English. Stockholm, Sweden: Lund University.

Badger, R., \& White, G. (2000). A process genre approach to teaching writing. ELT Journal, 54(2), 153 - 160.

Coe, R. M., \& Gutiérrez, K. (1981). Using problem-solving procedures and process analysis to help student with writing problems. College Composition and Communication, 32(3), 262-271. Retrieved from http://www.jstor.org/stable/356189

Cornwell, J., \& Robertson, S. A (Eds). (2011). Guidelines for Academic writing and Referencing. Education Department. Grahamstown, South Africa: Rhodes University.

Creme, P., \& Lea, M. R. (2008). Writing at university: A guide for students (3rd Ed.). New York, NY: Open University Press.

Davies, A. (2008). Assessing Academic English Testing English Proficiency 1950-89. The IELTS Solution.

Grami, G. M. A. (2010). The Effects of Integrating Peer Feedback into University-Level ESL Writing Curriculum: A Comparative Study in a Saudi Context. (Unpublished doctoral dissertation submitted to Newcastle University, School of Education, Communication and Language Sciences). Retrieved August 21, 2019, from https://theses.ncl.ac.uk/dspace/bitstream/10443/933/1/grami

Greetham, B. (2001). How to write better essays. Palgrave: Basingstoke.

Jones, R. (2015). Academic writing plagiarism across Europe and beyond. Conference Proceedings. Brno: Mendelu Publishing Centre.

Jordan, R. R. (2012). English for Academic Purposes: A guide and resource book for teachers. Cambridge: Cambridge University Press.

Mbirimi,V. (2012). Academic writing challenges faced by first year B.Ed. students at a South African university. The school of education. Faculty of Humanities. University of the Witwatersrand: Johannesburg.

Meltem, T. E. (2007). Constructivist Approach to developing academic Writing skills. DELSU: Atilim University.

Mirza, O. (n.d). Characteristics of academic writing. Retrieved August 01, 2019, from http://www.writeawriting.com/academic-writing/characteristics-academic-writing/

Moore, S. \& Murray, R. \& (2006). A handbook of academic writing: A fresh approach. New York, NY: Open University Press.

Morley-Warner, T. (2009). Academic writing is a guide to writing in a university context. Sydney: Association for Academic Language and Learning.

Mutwarasibo, F. (2013). Promoting university students' collaborative learning through instructor-guided writing groups. International Journal of Higher Education, 2(2), 13-21.

Nampala, K. (2010). English for Academic Purposes. Centre of External Studies: The University of Namibia.

Neely, S. D. (2005). Academic literacy. (2nd Ed.). New York, NY: Pearson Education.

Nightingale, P. (2000). Improving student writing. In S. Makoni (Ed.). Improving teaching and learning in higher education: A handbook for Southern Africa (pp. 131-166). Johannesburg, South Africa: Witwatersrand University Press.

Tardy, C. M. (2010). Writing for the world: Wikipedia as an introduction to academic writing. English Teaching Forum, 1, 12-27

Whitaker, A. (2009). Academic writing guide: A step-by-step guide to writing academic papers. Bratislava, Slovakia: City University of Seattle.

Yagoda, B. (2006). The seven deadly sins of student writers. The Chronicle of Higher Education, 53(3), B13. Retrieved January 16, 2019, from ProQuest Education Journals. 